\title{
Effects of Resistance Training on Hdiponectin, Testosterone and Cortisol Levels in Untrained Men
}

\author{
Masoud Zamani (PhD) \\ Department of Exercise \\ Physiology, Islamic Azad \\ University, Central Tehran Branch, \\ Tehran, Iran \\ Maghsoud Peeri (PhD) \\ Department of Exercise \\ Physiology, Islamic Azad \\ University, Central Tehran Branch, \\ Tehran, Iran \\ Mohammad-Ali Azarbayjani \\ (PhD) \\ Department of Exercise \\ Physiology, Islamic Azad \\ University, Central Tehran Branch, \\ Tehran, Iran \\ Hasan Matinhomaee (PhD) \\ Department of Exercise \\ Physiology, Islamic Azad \\ University, Central Tehran Branch, \\ Tehran, Iran \\ Corresponding author: \\ Maghsoud Peeri \\ Email: mpeeri@iauctb.ac.ir \\ Tel: +982188562484 \\ Address: Islamic Azad University, \\ Central Tehran Branch, Tehran, \\ Iran \\ Received : 31 Oct 2015 \\ Revised: 01 Nov 2015 \\ Accepted: 07 Nov 2015
}

\begin{abstract}
Background and Objective: Adipose tissue secrets various hormones including adiponectin, which is closely related to weight control and energy, balance. This study investigated the effects of resistance training on adiponectin, testosterone and cortisol levels in untrained men.
\end{abstract}

Methods: Forty untrained men (mean age of 23.0土2.66 years, mean weight of 67.43 $\pm 4.96 \mathrm{~kg}$ ) were randomly and equally assigned into groups of upper extremity resistance training, lower extremity resistance training, combined resistance training, and control. The subjects performed eight weeks of weight training, three sessions per week (five sets of 60 85\% one repetition maximum). Blood sampling was done prior to the start of the program, after the fourth week, and after the eight week. Alpha level was set to 0.05 for all statically analyses.

Results: Repeated measures ANOVA showed that eight weeks of upper extremities training significantly decreased body fat percentage $(\mathrm{p}=0.002,7.39 \%)$, and significantly increased adiponectin $(\mathrm{p}=0.000 ; 90.42 \%)$ and testosterone $(\mathrm{p}=0.002 ; 24.19 \%)$ levels. In the lower extremities training group, body fat percentage $(p=0.006,7.39 \%)$ decreased significantly, while adiponectin $(p=0.012 ; 87.82 \%)$ and testosterone $(p=0.000 ; 23.54 \%)$ levels increased significantly compared to the pretest. Eight weeks of combined training significantly increased BVI $(p=0.006,1.00 \%)$, muscle mass $(p=0.007,2.24 \%)$, and adiponectin $(p=0.000,91.56 \%)$ level. However, cortisol level decreased $(p=0.017,19.17 \%)$ after four weeks of training.

Conclusion: Upper and lower extremities resistance trainings significantly change testosterone levels. Different types of resistance training significantly increases serum adiponectin level and changes body composition, which are effective in prevention of cardiovascular diseases.

Keywords: Resistance Training, Adiponectin, Testosterone, Cortisol. 


\section{INTRODUCTION}

Obesity is a major health problem worldwide with a rising prevalence in both developed and developing countries (1). Considerable efforts have been expended to control or prevent this health problem (2). Obesity is also a known risk factor for cardiovascular disease. Adipose tissue secrets important proteins known as adipocytokines, which cause several biological outcomes. Adiponectin is an adipocytokine that can be considered an important biomarker of cardiovascular diseases (3-6). It is reported that adiponectin has anti-atherosclerotic and antiatherogenic effects (7). On the other hands, some evidences indicate that testosterone may control the secretion of adiponectin from fat cells. This may be the reason for higher incidence of atherosclerosis in men, since women have higher adiponectin levels compared to men (8). Testosterone is thought to have a potential anti-diabetic effect in men (9). Laughlin et al. reported a positive correlation between testosterone and adiponectin levels, and indicated that glococorticoids control the expression of adiponectin (10). Since adiponectin may be a marker of cardiovascular disease, lower adiponectin levels could be associated with high incidence of coronary heart disease (11). While some studies show that endurance training have positive effects on reducing the risk of cardiovascular disease (12), there are some reports that recommend strength training for maintenance of fitness in all age groups (13). Previous studies have shown that glucocorticoids control the expression of adiponectin, while there are contradicting results on the effects of resistance training. For example, some studies have shown that 12 weeks of resistance training with moderate intensity cause a significant increase in adiponectin levels, while others demonstrated no significant change in serum adiponectin levels $(14,15)$. Olson et al. reported that the level of serum adiponectin increased following one year of resistance training (two sessions per week, every 48 hours with 8 to 10 repetitions) in 16 overweight women (16). In spite of various effects of resistance training on level of different hormones compared to other types of training, the exact effect of resistance training on adipokines is not clear. Resistance trainings include upper body and lower body workouts. Training protocols used by bodybuilders may be highly acceptable for teenagers (17). Considering the probable association of adipocytokines, testosterone and physical activity with cardiovascular disease, the present study aimed to determine the effects of different types of resistance training on adiponectin, testosterone, and cortisol levels in untrained men.

\section{MATERIAL AND METHODS}

In this experimental study, 40 healthy untrained young men with mean age of $23.8 \pm 2.66$ years and mean weight of $67.43 \pm$ $4.96 \mathrm{~kg}$ were enrolled. The participants had no history of participation in any regular physical activity. All the participants were examined by a physician and no indication of cardiovascular, metabolic, respiratory or renal disease was present nor did they have any orthopedic injuries that limited their physical activities. They were randomly assigned into four groups consisting of lower extremities training group (squat, launch, leg press, leg extensions, leg curl and seated calf raise), upper extremities training group (bench press, rowing, shoulder military press, lat pull-down, biceps and triceps curl), combined resistance training group (bench press, leg press, lat pulldown, squat, biceps curl and seated calf raise), and control group. The exercises included one set of 8 to 12 repetitions at $60 \%$ maximum capability per session, and four sets of 6 to 8 repetitions at $80-85 \%$ maximum capability. There was a two-minute rest between each set of training and a three-minute rest between every workout. At the beginning of each session, the subjects performed jogging and stretching exercises for 10 minutes to warm up before the weight training exercises. At the end of each session, the subjects did jogging and stretching exercises to slow down the repetition. Subjects in the exercise groups were asked to avoid any types of exercise during the study other than the instructed workouts. In order to receive sufficient recovery time and avoid overtraining, the intensity of exercises was decreased to $60-85 \%$ of maximum capability after the new repetition 
maximum (RM) was determined. The participants in the control group were asked to perform their regular daily activities and avoid taking part in any type of new physical activity. On the first day of the study, weight, height, body composition, and strength (one RM) of each subject were measured. Body composition was assessed by a body composition analyzer (BC-418MA). Body mass index (BMI) was calculated as bodyweight in kilograms divided by height in meters squared $\left(\mathrm{Kg} / \mathrm{m}^{2}\right)$. The exercise protocol included 8 weeks of daily weight training. The entire training protocol lasted about 70 minutes per session. All subjects followed a similar diet (55\% carbohydrate, $15 \%$ protein and $30 \%$ fat) for three days until the time of blood sampling. They were also asked to go to bed at 11:00 P.M. Blood samples were collected before the intervention, at the end of the fourth week, and 24 hours after the last training session followed by 12 hours of fasting. Collected samples were analyzed to measure the serum levels of leptin, adiponectin, testosterone, and cortisol. This study was approved by the ethics committee of Sports Research Center (Code: SSRC.REC.1394.102). Written consent was obtained from all subjects before the start of the exercise protocol.
Blood collection: After 12 hours of fasting, blood sample was taken $(5 \mathrm{ml})$ from the right hand's antecubital vein in a sitting position prior to the start of the exercise program, at the end of the fourth week, and after eighth week of training. Each session was planned in a way that 10 hours of recovery was given to every participant prior to blood sampling. The blood samples were collected in tubes and kept at room temperature to allow coagulation. They were then centrifuged for 10 minute at 3500 rpm. The serum was separated and kept in a small tube at $-80{ }^{\circ} \mathrm{C}$ for further analysis. Biochemical analysis for measuring serum adiponectin level was performed using ELISA method and commercial kits (BOSTER Co. with $60 \mathrm{pg} / \mathrm{mg}$ sensitivity). Total testosterone (ng/mm) and cortisol levels were measured by chemiluminescent assay using a Siemens system (Germany) and commercial kits.

Statistical analysis: Data were calculated as mean \pm standard deviation (SD). The data was analyzed using test of normality, ANOVA, repeated measures ANOVA, Friedman test (when required) and Kruskal-Wallis test. Post hoc tests including Bonferroni, Scheffe, Tukey, Mann-Whitney $U$ test and Wilcoxon test were also used. All data were analyzed by SPSS software (version 20) with the alpha level set to 0.05 .

Table 1- Characteristics of untrained men in each study group

\begin{tabular}{cccccr}
\hline $\begin{array}{c}\text { Training } \\
\text { groups }\end{array}$ & Age (years) & Height $(\mathrm{Cm})$ & Weight $(\mathrm{kg})$ & Body fat $(\%)$ & BMI $\left(\mathrm{kg} / \mathrm{m}^{2}\right)$ \\
\hline $\begin{array}{c}\text { Upper } \\
\text { extremities }\end{array}$ & $24.15 \pm 2.77$ & $170.7 \pm 6.76$ & $70 \pm 3.32$ & $15.6 \pm 4.83$ & $23 \pm 1.49$ \\
$\begin{array}{c}\text { Lower } \\
\text { extremities }\end{array}$ & $21 \pm 0.79$ & $174.6 \pm 8.22$ & $65.13 \pm 7.39$ & $15.7 \pm 4.85$ & $23.5 \pm 3.15$ \\
Combined & $21.20 \pm 0.76$ & $176.2 \pm 1.55$ & $66.52 \pm 3.96$ & $19.1 \pm 3.30$ & $25 \pm 2.83$ \\
& & & & $15.7 \pm 4.88$ & $23.90 \pm 2.13$ \\
Control & $22.26 \pm 2.23$ & $175.20 \pm 5.07$ & $68.10 \pm 3.96$ & & \\
\hline
\end{tabular}

Data are represented as mean \pm SD 
Figure 1- Mean and SD of serum adiponectin levels (ng/ml) in the fourth and eighth week

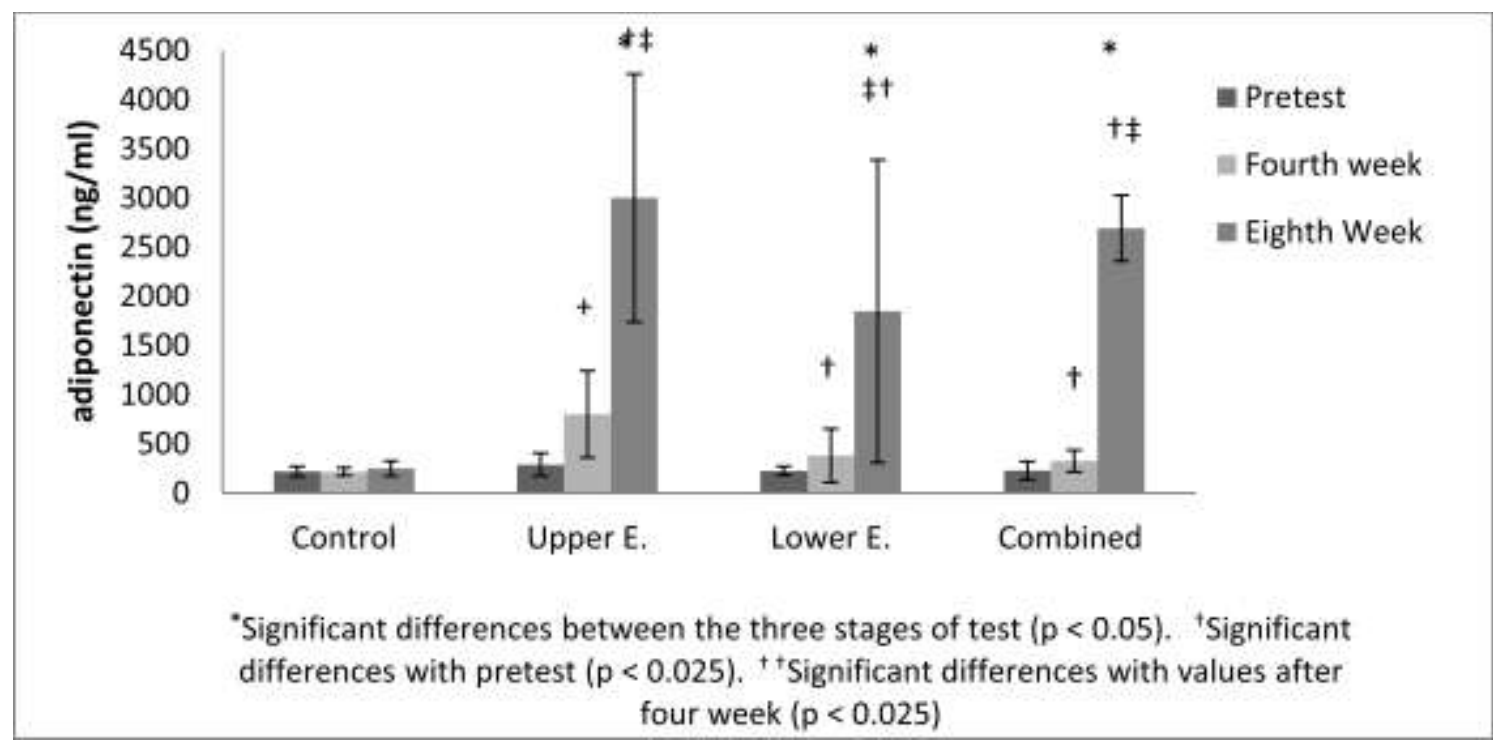

Table 2- Anthropometric and physiological measurements of the study groups according to the time of measurement

\begin{tabular}{|c|c|c|c|c|c|c|}
\hline \multirow[t]{2}{*}{ Variables } & \multirow[t]{3}{*}{ Group } & \multicolumn{3}{|c|}{ Time of measurement } & \multicolumn{2}{|c|}{ P-Value } \\
\hline & & Pretest & Fourth week & Eighth Week & Within & Between \\
\hline & & Mean \pm SD & Mean \pm SD & Mean \pm SD & Groups & Groups \\
\hline \multirow[t]{4}{*}{ BMI $\left(\mathrm{kg} / \mathrm{m}^{2}\right)$} & Upper E & $24.15 \pm 2.76$ & $23.78 \pm 3.09$ & $23.91 \pm 2.73$ & $0.006^{*}$ & $0.007^{* *}$ \\
\hline & Lower E & $21.10 \pm 0.79$ & $21.10 \pm 0.54$ & $21.16 \pm 0.49$ & & \\
\hline & Combined & $21.38 \pm 0.76$ & $21.72 \pm 0.66$ & $21.79 \pm 0.61 \dagger$ & & \\
\hline & Control & $22.26 \pm 2.23$ & $21.18 \pm 0.92$ & $21.17 \pm 1.04$ & & \\
\hline Body fat & Upper E & $18.58 \pm 2.25$ & $17.87 \pm 1.78$ & $17.30 \pm 1.86 \dagger$ & $0.002^{*}$ & $0.030^{* *}$ \\
\hline \multirow[t]{3}{*}{ percentage } & Lower E & $13.53 \pm 0.84$ & $13.61 \pm 0.65$ & $12.63 \pm 0.79 \dagger$ & $0.006^{*}$ & \\
\hline & Combined & $12.78 \pm 2.41$ & $12.63 \pm 2.02$ & $12.83 \pm 1.59$ & & \\
\hline & Control & $17.26 \pm 5.54$ & $17.16 \pm 5.23$ & $17.24 \pm 5.07$ & & \\
\hline Muscle mass & Upper E & $53.73 \pm 1.24$ & $53.93 \pm 1.86$ & $54.64 \pm 1.62$ & $0.007^{*}$ & 0.173 \\
\hline \multirow[t]{3}{*}{ percentage } & Lower E & $49.79 \pm 6.31$ & $49.94 \pm 5.98$ & $50.51 \pm 5.88$ & & \\
\hline & Combined & $54.91 \pm 1.33$ & $56.11 \pm 1.72$ & $56.17 \pm 1.29 \dagger$ & & \\
\hline & Control & $50.55 \pm 4.46$ & $50.18 \pm 5.81$ & $50.17 \pm 6.11$ & & \\
\hline
\end{tabular}

The result of analysis indicated that the data was not normally distributed. The result of Kruskal-Wallis, MannWhitney U test, and Bonferroni correction indicated significant differences between the groups $(\mathrm{p}<0.05)$.

*significant difference between three stages of training

$\dagger$ significant difference between post-test data within groups

$* *$ significant difference between the four groups $(\mathrm{p}<0.025)$ 


\section{RESULTS}

Eight weeks of upper extremity training significantly decreased body fat percentage $(\mathrm{p}=0.002)$, and increased plasma levels of adiponectin $\quad(\mathrm{p}=0.000)$ and testosterone $(\mathrm{p}=0.002)$. Lower extremities training significantly decreased body fat percentage $(\mathrm{p}=0.006)$, and increased plasma levels of adiponectin $\quad(p=0.012)$ and testosterone $(\mathrm{p}=0.000)$. In the combined resistance training group, eight weeks of training significantly increased BMI $(\mathrm{p}=0.006)$, muscle mass $(\mathrm{p}=0.007)$ and serum adiponectin level $(p=0.000)$. However, plasma cortisol level in this group reduced significantly following four weeks of training (Figure 1).

There were significant differences between the level of serum adiponectin in the experimental groups and the control group following eight weeks of training. The Eight weeks of training significantly changed serum testosterone levels $(\mathrm{p}=0.025)$. The serum testosterone levels significantly increased in the upper and lower extremities groups compared to the control group $(p=0.008)$. The body fat percentage changed significantly after eight weeks of training $(p=0.030)$. In addition, there was a significant difference between body fat percentage in the combined training group and the upper extremities group $(\mathrm{p}=0.008)$. The mean BMI of the experimental groups changed significantly after eight weeks of training $(\mathrm{p}=0.007)$. There was also a significant difference between mean BMI of the combined training group and the upper extremities group $(\mathrm{p}=0,008)$ (Table 2).

\section{DISCUSSION}

The results showed that eight weeks of upper and lower extremities resistance training significantly increased serum testosterone level. Testosterone is a predictive factor of cardiovascular diseases that plays a significant role in muscle growth and hypertrophy (10, 18). Four weeks of lower extremities training significantly increases testosterone, probably because bigger muscle groups are involved in this type of training. In addition, the intensity of exercise programs may contribute to these changes. Gote et al. have shown that performing resistance training with $80 \% 1 \mathrm{RM}$ significantly increases testosterone level (19). Testicular circulation, increased activity of sympathetic nervous system, increased volume of plasma, increased discharge from testicles, and secretion of testosterone in response to vascular dilations are thought to be involved in testosterone level increase in response to different exercise programs. The results of this study showed that resistance training increases resting plasma testosterone level, which is in agreement with the results of some previous studies (20,21). Another study demonstrated that exercise on arm ergometer causes higher tension in muscles and as a result, more type-II motor fibers are recruited. Since this type of fibers have higher glycolytic and lower oxidative capacity, the rate of lactate production increases (22). Although the level of lactate was not measured in this study, the increase in testosterone levels may be due to the type of exercise performed in the training protocol. On the other hand, there is a high number of androgenic receptors in upper extremities (chest) that shows less response to strength training exercises compared to the muscles in lower extremities (Vastus lateralis muscle) (23). Therefore, combining the upper and lower extremities trainings may not cause any significant alteration. Inconsistent with these findings, some studies reported that full body workouts increase hormonal response $(24,25)$. The combined trainings significantly increased BMI after eight weeks. There seems to be an inverse association between BMI and testosterone level. Moreover, the muscle mass increased in all exercise groups. However, this increase was only significant in the combined training group. Prolonged neuroendocrine adaptation may be associated with the volume and intensity of training (18).

Eight weeks of upper and lower extremities training significantly decreased body fat percentage. Some reports indicate that different durations of resistance training may decrease body fat by $1-9 \%$ (26). The level of testosterone has a negative association with the level of central fat in men $(27,28)$. Therefore, decrease in body fat percentage, increases testosterone levels. Epidemiologic studies have shown a mutual relationship between obesity and serum testosterone level (29). Thus, it can be concluded that the trainings can affect both body fat percentage and testosterone level. The combined training program significantly 
decreased cortisol levels after four weeks, while no significant alteration was observed in other training groups. Goto et al. demonstrated that intensive resistance training ( $80 \%$ 1RM) and speedy movement do not cause significant alteration in cortisol levels (30). This is partially in agreement with the results of the present study (upper and lower extremities trainings). Several factors such as individual differences, nutritional status, and training conditions may affect exercise-induced cortisol level alterations (18). The mild and insignificant decrease in serum concentration of cortisol after eight weeks of upper and lower extremities trainings can be attributed to adaptation of the nervous system to exercise. The decreased cortisol levels in upper and lower extremities trainings seems to be proportional to increased testosterone levels in these types of trainings, which indicates hormonal interactions $(18,31)$. The serum level of adiponectin in all training groups increased after eight weeks of training. This is consistent with another study that showed moderate-tohigh intensity resistance training significantly increases adiponectin levels (14). However, study of Ahmadzadeh et al. showed that 12 weeks of strength training (three days per week with 50-60\% intensity, 1RM) and 12 weeks of endurance training (including running at 75$85 \%$ maximum heart rate for three days per week) did not cause any significant change in serum adiponectin levels (15). The discrepancies between the results of the present study and other studies may be due to differences in the age, gender, weight and BMI of the participants, and exercise protocol (32, 33). There was a positive correlation between intensity of exercise and adiponectin level (17). All exercise groups in the present study performed high intensity training causing a significant increase in their adiponectin levels (with no significant difference between training groups). It has been shown that resistance training increases protein synthesis in muscles that ultimately brings about an increased muscle mass. This enhances resting energy consumption, which consequently decreases body fat percentage (34). Ryan et al. reported the inverse association of serum leptin and adiponectin levels with body fat percentage
(35). In addition, resistance training increases glucose removal by peripheral tissues in response to acidosis, lactate accumulation, increased adrenal sympathetic nerve activity, energy consumption and glycogen depletion. It also regulates glycolysis that in turn increases insulin sensitivity. On the other hand, an increase in BMI (increase in muscle mass and decrease in fat tissue) gives rise to an increase in serum levels of adiponectin (36). Therefore, the increase in adiponectin levels of these groups may be attributed to increased muscle mass in combined trainings and decreased body fat percentage in lower and upper extremities trainings. Simpson et al. claimed that performing aerobic exercise and sufficiently long or intense resistance trainings decreased body fat percentage, which in turn caused a significant increase in adiponectin levels (12). Therefore, the increase in serum adiponectin level in the present study can be attributed to changes in the body composition in response to the trainings.

\section{CONCLUSION}

The results of this study showed that resistance training significantly increases adiponectin levels. Eight weeks of upper and lower extremities trainings reduce body fat percentage and testosterone level, respectively. Moreover, muscular mass increases after eight weeks of combined trainings. However, more studies are required to determine the exact mechanisms involved in alteration of testosterone and cortisol levels, and their effects on changes in the body composition.

\section{ACKNOWLEDGEMENTS}

This article was derived from a $\mathrm{PhD}$ thesis in exercise physiology at Islamic Azad University of Tehran. The authors would like to express their appreciation to the research supervisor, Dr Maghsoud Peeri, and all the participants in this study. They would also like to thank the personnel of Kavosh Laboratory in Gorgan, for performing laboratory analysis.

\section{CONFLICT OF INTEREST}

All contributing authors declare no conflicts of interest. 


\section{REFERENCES}

1. Calderon KS, Yucha CB, Schaffer SD. Obesity-Related Cardiovascular Risk Factors: Intervention Recommendations to Decrease Adolescent Obesity. J Pediatr Nurs. 2005. 20(1): 3-14. PMID: 15834354.

2. DeMelo CM, Tirapegui J, Cohen D, Marchini JS, Ribeiro SM. Nutritional status and energy expenditure after a programme of nutrition education and combined aerobic/resistance training in obese women. Eur J Clin Nutr Metab2010; 5(4): 180-186. doi:10.1016/j.eclnm.2010.04.001.

3. Shimada K, Miyazaki T, Daida H. Adiponectin and atherosclerotic disease. Clin Chim Acta. 2004; 344(1-2): 1-12. PMID: 15149866.

4. Berg AH, CombsTP, Scherer PE. ACRP30/adiponectin: An adipokine regulating glucose and lipid metabolism. Trends Endocrinol Metab. 2002; 13(2): 84-89. PMID: 11854024.

5. Azarbayjani MA, Abedi B. Comparison of Aerobic, Resistance and Concurrent Exercise on Lipid Profiles and Adiponectin in Sedentary Men. Knowledge \& Health 2012; 7(1): 32-38.

6. Yang WS1, Lee WJ, Funahashi T, Tanaka S, Matsuzawa Y, Chao CL, et al. Plasma adiponectin levels in overweight and obese Asians. Obese Res. 2002. 10(11): 1104-1110. PMID: 12429873.

7. Fangand X, Sweeney G. Mechanisms regulating energy metabolism by Adiponectin in obesity and diabetes. Biochem Soc Trans . 2006. 34(5): 708-801. PMID: 17052201.

8.Meier U, Gressner AM. Endocrine regulation of energy metabolism: review of pathobiochemical and clinical chemical aspects of leptin, ghrelin, adiponectin, and resistin. Clin Chem. 2004; 50(9): 1511-25. PMID: 15265818.

9. Hotta K, Funahashi T, Arita Y, TakahashiM, Matsuda M, Okamato Y, et al. Plasma concentration of a novel, adipose specific protein, adiponectin, in type 2 diabetic patients. Arterioscler thromb Vasc Biol. 2000; 20(6): 1595-9. PMID: 10845877.

10. Laughlin GA, Barrett-Connor E, May S. Sex-specific determinants of serum adiponectin in older adults: the role of endogenous sex hormones. Int $\mathrm{J}$ Obes (Lond). 2007; 31(3): 457-65. PMID: 16819528.

11. Hotta K, Funahashi T, Bodkin NL, Ortmeyer HK, Arita Y, Hansen BC, Matsuzawa Y. Circulating concentrations of the adipocyte protein adiponectin are decreased in parallel with reduced insulin sensitivity during the progression to type 2 diabetes in rhesus monkeys. Diabetes. 2001 May;50(5):1126-33. PMID: 11334417.

12. Braith RW, Beck DT. Resistance exercise: training adaptations and developing a safe exerciseprescription. Heart Fail Rev. 2008; 13(1): 69-79. PMID: 17932746.

13. Duncan GE, Anton SD. Prescribing exercise at variedlevels of intensity and frequency: Arandomized trial . Arch Intern Med 2005; 165(20): 2362-9. PMID: 16287765 .
14. Fatouros IG, Tournis S, Leontsini D, Jamurtas AZ, Sxina M, Thomakos $\mathrm{P}$, et al. Leptin and adiponectin responses in overweight Inactive elderly following resistance training and detraining are Intensity related. J Clin Endocrinol Metab. 2005; 90(11): 5970-5977. PMID: 16091494.

15. Ahmadizad S, AH Haghighi, Hamedinia MR. Effects of resistance versus endurance training on serum adiponectin and insulin resistance index. Eur J nol. 2007; 157(5): 625-631. PMID: 17984242.

16. Olson TP, Dengel DR, Leon AS, Schmitz KH .Changes in inflammatory biomarkers following one-year of moderate resistance training in overweight women. Int J Obes (Lond). 2007; 31(6), 996-1003. PMID: 17299382.

17. Calder AW, Chilibeck PD, Webber CE, Sale DG. Comparison of Whole and Split Weight Training Routines in Young Women. Can J Appl Physiol. 1994; 19(2): 18599. PMID: 8081322

18. Kraemer WJ, Ratamess NA. Hormonal Responses and Adaptations to Resistance Exercise and Training. Sports Med 2005; 35(4): 339-361. PMID: 15831061.

19. Goto K, Takahashi K, Yamamoto M, Takamatsu K. Hormone and recovery responses to resistance exercise with slow movement. J Physiol Sci. 2008; 58(1): 7-14. PMID: 18186955

20. Ahtiainen JP, Pakarinen A, Alen M, Kraemer WJ, Häkkinen K. Muscle hypertrophy, hormonal adaptations and strength development during strength training in strength-trained and untrained men. Eur J Appl Physio. 2003; 89(6): 555-563. PMID: 12734759.

21. Kraemer WJ, Häkkinen K, Newton RU, Nindl BC, Volek JS, McCormick M, et al. Effects of heavy resistance training on hormonal respons patterns in younger versus older men. J Appl Physiol. 1999; 87(3): 982-992. PMID: 10484567.

22. Louhevaara V, Sovijarvi A, Ilmarinen J, Teraslinna P. Differences in cardiorespiratory responses during and after arm cranking and cycle exercise. Acta Physiol Scand. 1990 ; 138(2): 133-43. PMID: 2316376.

23. Rønnestad BR1, Egeland W, Kvamme NH, Refsnes PE, Kadi F, Raastad T. Dissimilar effects of one- and three-set strength training on strength and muscle mass gains in upper and lower body in untrained subjects. J Strength Cond Res. 2007; 21(1): 157-63. PMID: 17313291.

24. Ha kkinen K, Pakarinen A, Kraemer WJ, Ha“kkinen $\mathrm{R}$, Valkeninen H, Alen M. Selective muscle hypertrophy, changes in EMG, and force, and serum hormones during strength training in older women. JAppl Physiol. 2001; 91(2): 569-80. PMID: 11457767.

25. Spiering BA, Kraemer WJ, Vingren JL, Ratamess NA, Anderson JM, Armstrong LE, et al. Elevated endogenous testosterone concentrations potentiate muscle androgen receptor responses to resistance exercise. J Steroid Biochem Mol Biol. 2009; 114: 195-9. PMID: 19429451.

26. Fleck SJ, Kraemer WJ. Designing Resistance Training Programs. $2^{\text {nd }}$. Champaign, IL: Human Kinetics Books; 1997. 
27. Laughlin GA, Barrett-Connor E, May S. Sex-specific determinants of serum adiponectin in older adults: the role of endogenous sex hormones. Int $\mathrm{J}$ Obes (Lond). 2007; 31(3): 457-65. PMID: 16819528.

28. Couillard C1, Gagnon J, Bergeron J, Leon AS, Rao DC, Skinner JS, et al. Contribution of body fatness and adipose tissue distribution to the age variation in plasma steroid hormone concentrations in men. the HERITAGE Family Study. J Clin Endocrinol Metab. 2000; 85(3): 1026-1031. PMID: 10720034.

29. Brand JS, van der Tweel I, Grobbee DE, EmmelotVonk MH, van der Schouw YT. Testosterone, sex hormone-binding globulin and the metabolic syndrome: a systematic review and meta-analysis of observational studies. Int J Epidemiol. 2011; 40(1): 189-207. PMID: 20870782.

30. Goto K, Ishii N, Kizuka T, Kraemer RR, Honda Y, Takamatsu K. Hormonal and metabolic responses to slow movement resistance exercise with different durations of concentric and eccentric actions. Eur J Appl Physiol. 2009; 106(5): 731-739. PMID: 19430944.

31. West DW, Kujbida GW, Moore DR, Atherton P, Burd NA, Padzik JP, et al. Resistance exercise-induced increases in putative anabolic hormones do not enhance muscle protein synthesis or intracellular signaling in young men. J Physiol. 2009; 587(21): 5239-47. PMID: 19736298.
32. Ibez J, Izquierdo M, Martnez-Labari M, Ortega F, Grijalba A, Forga L, et al. Resistance Training Improves Cardiovascular Risk Factors in Obese Women Despite a Significative Decrease in Serum Adiponectin Levels. Obesity (Silver Spring). 2010; 18(3): 535-541. PMID: 19713947.

33. Klimcakova E, Polak J, Moro C, Hejnova J, Majercik M, Viguerie N, et al. Dynamic strength training improves Insulin sensitivity without altering plasma levels and gene Expression of adipokines in subcutaneous adipose tissue in obese men. J Clin Endocrinol Metab. 2006; 91(12): 5107-5112. PMID: 16968804.

34. Hakimi M, Ali-Mohammadi M. Comparison between the effects of a resistance training combined with massage, PNF and static stretching on performance in non-athlete male students. Int J Sport Studies. 2014; 4(1): 37-44.

35. Ryan AS1, Berman DM, Nicklas BJ, Sinha M, Gingerich RL, Meneilly GS, et al. Plasma adiponectin and leptin levels, body composition, and glucose utilization in adult women with wide ranges of age and obesity. Diabetes Care. 2003; 26(8): 2383-8. PMID: 12882866.

36. Cnop M1, Havel PJ, Utzschneider KM, Carr DB, Sinha MK, Boyko EJ, et al. Relationship of adiponectin to body fat distribution, insulin sensitivity and plasma lipoproteins: evidence for independent roles of age and sex. Diabetologia. 2003; 46(4): 459-69. PMID: 12687327. 